\title{
Possible Mechanism of Porosome-Mediated Exosome Release
}

WON JIN CHO ${ }^{1}$, BRENT FORMOSA ${ }^{1}$, MZIA G. ZHVANIA ${ }^{1,2,3}$, DOUGLAS J. TAATJES ${ }^{1,4}$,

5 IONITA GHIRAN ${ }^{1,5}$, BHANU P. JENA ${ }^{1,6,7,8^{*}}$,

Key terms: Neuronal porosome, beta cell porosome, neurotransmitter and insulin secretion, exosome

${ }^{1}$ Viron Molecular Medicine Institute, One Boston Place, $26^{\text {th }}$ Floor, Boston, MA 02108 USA;

${ }^{2}$ School of Natural Sciences and Medicine, Ilia State University, 3/5 K. Cholokashvili Av., Tbilisi $0162 \&{ }^{3}$ Department of Brain Ultrastructure and Nanoarchitecture, I Beritashvili Center of Experimental Biomedicine, Tbilisi 0160, Georgia; ${ }^{4}$ Department of Pathology and Laboratory Medicine, Microscopy Imaging Center, University of Vermont College of Medicine, Burlington, VT 05405, USA.; ${ }^{5}$ Division of Allergy and Inflammation, Beth Israel Deaconess Medical Center, Harvard Medical School, 3 Blackfan Circle, Boston, Massachusetts 02115, USA; ${ }^{6}$ Department of Physiology, ${ }^{7}$ NanoBioScience Institute, ${ }^{8}$ Center for Molecular Medicine \& Genetics, School of Medicine, Wayne State University, Detroit, MI 48201, USA.

*Corresponding author and to whom reprint request should be addressed:

23 Bhanu P. Jena, Ph.D.

24 Wayne State University School of Medicine, 540 E. Canfield, 5245 Scott Hall, Detroit, MI 48201, USA. Tel: 248-885-3640

E-mail address: bjena@med.wayne.edu (B.P. Jena)

Disclosure statement: The authors have nothing to disclose. 


\section{ABSTRACT}

33 Supramolecular cup-shaped lipoprotein structures called porosomes embedded in the cell plasma 34 membrane mediate fractional release of intra-vesicular contents from cells during secretion. The 35 presence of porosomes, have been documented in many cell types including neurons, acinar cells 36 of the exocrine pancreas, growth hormone secreting cells of the pituitary, and mouse insulin37 secreting beta cell insulinomas called Min6. Electron micrographs of the nerve terminal in rat brain 38 and of Min6 cells, suggest that besides the docking, fusion and content release of neurotransmitter 39 containing synaptic vesicles and insulin containing granules, multi-vesicular bodies and exosome40 like vesicles are released at the porosome complex. To test this hypothesis, the porosome41 associated calcium transporting ATPase 1 [SPCA1] encoded by the ATP2C1 gene, was knocked42 out in Min6 cells using CRISPR, to study glucose-stimulated insulin and exosome release. In 43 agreement with electron micrographs, results from the study demonstrate a loss of both glucose44 stimulated insulin and exosome release in the ATP2C1 knockout Min6 cells. These results further confirm the role of the porosome complex in insulin secretion and establishes a new paradigm in porosome-mediated exosome release in beta cells of the endocrine pancreas. 


\section{INTRODUCTION}

49 Nearly 38 trillion cells composing the human body communicate with each other via secreted

50 biomolecules. In 1996, plasma membrane-associated 100-120 nm cup-shaped lipoprotein

51 structures called porosomes were discovered in the exocrine pancreas and subsequently in the

52 endocrine cells and neurons, that enable the secretion of biomolecules from cells (1-13).

53 Porosomes in neurons are approximately $15 \mathrm{~nm}$ cup-shaped lipoprotein structures with a central

54 plug, and are composed of nearly 30 proteins $(7,9,10)$. Porosomes mediate the kiss-and-run

55 mechanism of fractional release of intravesicular contents during cell secretion (3-10). In

56 porosome-mediated secretion, secretory vesicles temporarily dock and fuse at the porosome base

57 in the cell plasma membrane as opposed to complete collapse of the vesicle membrane with the cell plasma membrane to empty intravesicular contents during secretion. Glucose stimulated release of insulin stored in secretory vesicles in $\beta$-cells occur either by complete collapse of the vesicle membrane at the cell plasma membrane or the transient docking and fusion of secretory

61 vesicles at the base of porosomes. In agreement therefore, partially empty secretory vesicles accumulate in cells following secretion, as demonstrated in electron micrographs (11). In earlier studies, isolated porosomes from the exocrine pancreas and neurons, have been structurally and

64 functionally reconstituted into artificial lipid membranes and live insulin-secreting mouse 65 insulinoma cell line, Min6 $(4,7,11,12)$. In the past two decades, a large body of information provide 66 conclusive evidence of secretory defects resulting from mutation in genes expressing various 67 porosome proteins (13). Among these proteins, is the calcium transporting ATPase 1 [SPCA1] 68 encoded by the ATP2C1 gene. Glucose stimulated release of insulin stored in secretory vesicles in $69 \beta$-cells occur either by complete collapse of the vesicle membrane at the cell plasma membrane or 
71 reader on the structure of the porosome complex in the exocrine and endocrine pancreas and

72 neurons $(2,4,7)$, Figure 1 is presented, with secretory vesicles and the porosomes depicted in

73 pseudo color for clarity.

75 In addition to secretion of neurotransmitters, digestive enzymes or hormones, cells also

76 communicate with each other via secreted membrane-bounded nanostructured extracellular

77 vesicles called exosomes, first discovered and reported in 1983 as a selective externalization

78 mechanism of the transferrin receptor in sheep reticulocytes (14). Electron micrographic evidence

79 for such externalization of the transferrin receptor in vesicular form from sheep reticulocytes, was

80 demonstrated in 1985 (15). In the past 35 years, great progress has been made in our understanding

81 of the biology, function, and biomedical application of exosomes (16-18). Exosomes vesicles are

82 packaged with proteins, DNA, and RNA, that are destined for specific target cells in the body.

83 Such intercellular communication via exosomes has also been implicated in various pathologies

84 such as cancers, neurological disorders and inflammatory disease (16-18). While extracellular

85 vesicle cargo include plasma membrane and endosomal proteins, they may also contain materials

86 from various intracellular compartments such as the mitochondria. Recent studies report the

87 presence of mitochondrial DNA within extracellular vesicles (19, 20). Although, multi-vesicular

88 bodies may fuse at the cell plasma membrane to release their cargo, the molecular mechanism of

89 exosome release and or their cargo from various cell types, remains unclear.

91 The current study conducted in rat brain tissue and Min6 cells using electron microscopy (EM),

92 suggests the possible release of exosomes via the porosome complex. Syntaxin and the ATP2C1

93 gene product are among the nearly 30 porosome-associated proteins. To further test whether 
94 porosome are indeed involved in the release of exosomes in Min6 cells, glucose stimulated insulin

secretion assays were performed in control wild type (SCRM) and in ATP2C1 gene knocked-out Min6 cells using CRISPR. Results from the study confirms the release of exosomes via the porosome complex as observed in EM micrographs, demonstrating a loss of both glucosestimulated insulin secretion and exosome release in the ATP2C1 knockout Min6 cells. These results further establishes a new paradigm in porosome function in neurons and beta cells of the endocrine pancreas.

\section{MATERIALS AND METHODS}

\section{Rat brain tissue sections}

As previously published (7), Wistar rats, weighing approximately $115 \mathrm{~g}$ were used in the study. Animals were housed in a controlled environment (temperature $20-22{ }^{\circ} \mathrm{C}, 60 \%$ humidity, $12 \mathrm{~h}$ light/dark cycle) with free access to food and water. Following euthanasia using pentobarbital (100 $\mathrm{mg} / \mathrm{kg}$ ), animals underwent trans-cardiac perfusion with phosphate buffer saline $\mathrm{pH} 7.4$ containing $2.5 \%$ glutaraldehyde, prior to processing for electron microscopy (7).

\section{Min6 cell culture}

Min6 mouse insulinoma cells were cultured according to published procedure (2) in high-glucose (25 mM) Dulbecco's Modified Eagle Medium (DMEM) (Invitrogen) supplemented with 10\% fetal calf serum, $50 \mu \mathrm{M} \beta$-mercaptoethanol and antibotics (Penicillin and Streptomycin). Porosome isolations and electron microscopy were performed using Min6 cells grown to confluence in 100 x $13 \mathrm{~mm}$ sterile plastic petri dishes. Immunofluorescence microscopy was performed on Min6 cells grown to 75\% confluence in $35 \mathrm{~mm}$ petri dishes with glass bottom coverslips (MatTek, Ashland, MA). 
118 Min6 cell ATP2C1 knockout using CRISPR

119 ATP2C1 knock out Min6 cells were generated by genome editing using a CRISPR/Cas9 system.

120 In brief, pLentiCRISPR v2 plasmids that contained predesigned guide RNA targeting mouse

121 ATP2C1 (KO, 5'-TGATGCCGTCAGTATCACTG-3') and scrambled control guide RNA (SCRM, 122 5'-AAACCAAAGAGCCGAAGAAC-3') were obtained from GenScript (Piscataway, NJ). These

123 plasmids were then transfected into Min6 using Lipofcetamin 3000 (Invitrogen). Cells were 124 selected with puromycin $(0.15 \mathrm{ug} / \mathrm{ml})$ for 10 days until resistant populations emerged. After clonal 125 expansion of each cell, the knockout of ATP2C1 was confirmed via immunoblot.

PCR

128 The aliquots of each condition were collected, followed by PCR analysis using 2X DreamTaq 129 Green PCR Master Mix (2X) (Thermo Fisher Scientific) with random hexamer (Invitrogen) as 130 PCR primers.

\section{Statistical analysis}

133 All experiments were repeated at least three times, and all data are presented as the mean $\pm \mathrm{SD}$.

134 Statistical analysis was performed using student unpaired two-tailed t-test whose significance was 135 determined according to $\mathrm{p}$ values $(\mathrm{p}<0.01(* *), \mathrm{p}<0.05(*))$, no significance to n.s. between studied 136 groups, respectively. 


\section{Electron microscopy $($ EM)}

142 Rat brain EM: Transmission electron microscopy of rat brain was performed as described in a

143 previously published procedure (7). Briefly, rat brain was perfused with normal saline solution,

144 followed by phosphate buffer ( $\mathrm{pH} 7.4$ ) containing $2.5 \%$ glutaraldehyde. After perfusion, the brain

145 was carefully removed and diced into $1 \mathrm{~mm}^{3}$ pieces. The pieces of brain tissue were post-fixed in

146 phosphate buffer containing 1.5\% osmium tetroxide, dehydrated in graded ethanol and acetone,

147 and embedded in araldite. Tissue blocks were appropriately trimmed and the 40-50 nm sections

148 obtained were stained with lead citrate and examined under a JEOL JEM-100C transmission

149 electron microscope.

151 Min6 Cell EM: Transmission electron microscopy of Min6 cells was performed as described in a

152 previously published procedure $(8,9)$. Briefly, cells were fixed in $2 \%$ glutaraldehyde/2\%

153 paraformaldehyde in ice-cold phosphate buffered saline (PBS) for $24 \mathrm{~h}$, washed with buffer,

154 embedded in $2 \%$ SeaPrep agarose, followed by post-fixation for $1 \mathrm{~h}$ at $4{ }^{\circ} \mathrm{C}$ using $1 \% \mathrm{OsO}_{4}$ in 0.1

155 M cacodylate buffer. The sample was then dehydrated in a graded series of ethanol, through

156 propylene oxide, and infiltrated and embedded in Spurr's resin. Ultrathin sections were cut with a

157 diamond knife, retrieved onto 200 mesh nickel thin-bar grids, and contrasted with alcoholic uranyl

158 acetate and lead citrate. Grids were viewed with a JEOL 1400 transmission electron microscope

159 (JEOL USA, Inc., Peabody, MA) operating at 60 or $80 \mathrm{kV}$, and digital images were acquired with

160 an AMT-XR611 11 megapixel CCD camera (Advanced Microscopy Techniques, Danvers, MA). 


\section{Pseudo coloring of electron micrographs}

164 Transmission electron micrographs of Min6 cells were pseudo colored for clarity using the

165 published Basic Photoshop for Electron Microscopy approach

166 [http://www.nuance.northwestern.edu/]. The main purpose of this approach is to yield additional

167 valuable information for clarity and structural details that could easily be overlooked. The original

168 EM images are provided alongside the pseudo-colored images, for further authenticity and clarity.

\section{Immunofluorescence microscopy}

172 To determine the presence and distribution of insulin and the porosome-associated proteins

173 Syntaxin and ATP2C1 in control (SCRM) and ATP2C1-KO Min6 cells, immunofluorescence

174 studies were performed according to published procedures $(8,14)$. To determine the position of the

175 cell nucleus, cells were exposed to DAPI nuclear stain (Molecular Probes, Life Technologies,

176 Carlsbad, CA). Immunofluorescent images were acquired using an immunofluorescence FSX100

177 Olympus microscope through a 100x objective lens (numerical aperture $=1.40$ ) with illumination

178 at $405 \mathrm{~nm}, 488 \mathrm{~nm}$, or $647 \mathrm{~nm}$. The co-association of Syntaxin 1 and ATP2C1 and their cellular

179 distribution was determined by merging the fluorescent images.

\section{$181 \quad$ Fluorescent Immuno-colocalization Analysis}

182 Image analysis of colocalization was performed using JACop tool of Plugins in the ImageJ

183 (v1.53p). The comparative degree of colocalization for the SCRM and ATP2C1 KO was

184 calculated as mean Pearson's coefficients on the red and green channels. 


\section{Densitometric Analysis of Immunoblots}

187 Densitometry analysis of immunoblots was performed using the ImageJ (v1.53p) program.

188 Values were adjusted to the proper experimental conditions then the values were displayed under 189 each panel as a fold change.

191 Glucose-stimulated insulin secretion from Min6 cells

192 MIN6 cells grown to $75 \%$ confluency in $100 \times 13 \mathrm{~mm}$ sterile plastic petri dishes and glucose-stimulated

193 insulin release was estimated. All secretion assays were performed at room temperature $\left(25^{\circ} \mathrm{C}\right)$.

194 Cells were washed three times using 5ml/wash of PBS, pH 7.4, and incubated in $35 \mathrm{mM}$ glucose-

195 PBS. Since $30 \mathrm{mM}$ glucose demonstrated no significant change in insulin secretion over control, 196 and $35 \mathrm{mM}$ glucose did (data not shown), $35 \mathrm{mM}$ glucose was used in all assays carried out in this 197 study. Two hundred microliter aliquots were removed at times 0 , 10, and 30 min following $35 \mathrm{mM}$ 198 glucose incubation. The aliquots were centrifuged at 4,000 $\mathrm{x} g$ to remove any cells that may have

199 been aspirated, and $160 \mu \mathrm{l}$ of the supernatant was mixed with $40 \mu \mathrm{l}$ of $5 \mathrm{x}$ Laemmli reducing sample 200 preparation buffer (13), boiled for $2 \mathrm{~min}$, and resolved using SDS-PAGE followed by Western blot 201 analysis utilizing an insulin-specific antibody. Following completion of the secretion assays, cells 202 were solubilized in equal volumes of PBS, their protein concentration determined. To compare 203 total insulin in the control and reconstituted cells, equal volume of the cell lysate in Laemmli 204 reducing sample preparation buffer (13) was immunoblotted using insulin-specific antibodies.

205 Five micrograms of the cell lysate was also used in SDS-PAGE and Western blot analysis to 206 determine the immunoreactive presence of various porosome-associated proteins. Percent insulin 207 release were measured from the optical densities of insulin Western blots of the secreted and whole 208 cell lysates. 


\section{Western blot analysis}

211 Isolated Min6 homogenates from both control (SCRM) and ATP2C1-KO and the glucose-

212 stimulated insulin release medium in Laemmli buffer were resolved in a $12.5 \%$ SDS-PAGE,

213 followed by electrotransfer to $0.2 \mathrm{~mm}$ nitrocellulose membrane. The membrane was incubated for

214 1h at room temperature in blocking buffer (5\% nonfat milk in PBS pH 7.4 containing $0.1 \%$ Triton

$215 \mathrm{X}-100$ and $0.02 \% \mathrm{NaN}_{3}$ ) and immunoblotted for $2 \mathrm{~h}$ at room temperature with antibodies raised

216 against insulin (Santa Cruz Biotechnology Inc, Santa Cruz, CA), the porosome associated protein

217 ATP2C1 and actin (Santa Cruz Biotechnology Inc, Santa Cruz, CA), and the exosome marker

218 CD63 (Santa Cruz Biotechnology Inc, Santa Cruz, CA). All antibodies were used at a final

219 concentration of $0.2 \mu \mathrm{g} / \mathrm{ml}$ in blocking buffer. The immunoblotted nitrocellulose sheets were

220 washed in PBS ( $\mathrm{pH} 7.4$ ) containing $0.1 \%$ Tween, prior to incubation for $1 \mathrm{~h}$ at room temperature

221 in horseradish peroxidase-conjugated secondary antibodies at a dilution of 1:5,000 in blocking

222 buffer. The immunoblots were washed in PBS containing $0.1 \%$ Tween and processed for enhanced

223 chemiluminescence and exposure to X-Omat-AR film. The exposed films were then developed

224 and photographed.

225

226

227 RESULTS AND DISCUSSION

228 In the current study, close examination of electron micrographs of rat brain tissue and insulin

229 secreting Min6 cells, reveal the possible release of exosome-like vesicles measuring 15-20 nm in

230 diameter and or the secretion of their intra-vesicular contents, via the porosome complex. To test

231 the hypothesis that porosome are involved in exosome secretion, glucose stimulated insulin and 
exosome secretion from Min6 cells were performed in wild type SCRM control and

233 in ATP2C1 gene knocked-out Min6 cells using CRISPER. Results from the study confirms the

234 release of both insulin and exosomes via the porosome complex in Min6 cells.

Electron micrographs of rat brain tissue suggests cargo release from exosome-like vesicles

via fusion with synaptic vesicles docked at the porosome complex

238 Electron micrograph of rat brain tissue [Figure 2] shows the presence of 15-20 nm exosome-like

239 vesicles free or associated with 30-40 nm synaptic vesicles. Some of the exosome-like vesicles

240 appear to be generated from the mitochondria present within the synaptosome. Exosome-like

241 vesicles are also seen associated with synaptic vesicles docked at the neuronal porosome complex,

242 suggesting fusion and content release together with neurotransmitters. Multiple exosome-like

243 vesicles are sometimes found associated with a single synaptic vesicle. Similar to the clear synaptic

244 vesicles, the exosome-like vesicles appear clear with no electron dense material content.

245 Interestingly, exosome-like vesicles were never observed to be directly docked at the porosome

246 base for fusion and release.

Electron microscopy on Min6 cells reveal the release of exosome-like vesicles via the

\section{9 porosome complex}

250 In Min6 cells, multi-vesicular bodies are seen in electron micrographs. Occasionally, an insulin

251 containing granule is found fused with a multi-vesicular body. Such a multi-vesicular body fused

252 with an insulin containing granule, is seen docked and fused the porosome base, releasing intact

253 approximately $20 \mathrm{~nm}$ in diameter vesicles [Figure 3]. The porosome most likely is in the process

254 of secreting insulin in addition to the release of exosome-like vesicles, since most of the electron 
255 dense material (insulin) from within the secretory granule has been released. These electron

256 microscopy images further suggest that porosome complexes primarily involved in regulated

257 secretion of hormones, enzymes and neurotransmitters, may also participate in the regulated

258 release of exosomes and exosomal contents from cells. This hypothesis was further tested in Min6

259 cells.

261 Knockout of the porosome-associated protein gene ATP2C1 in Min6 cells result in loss of

262 glucose-stimulated insulin secretion

263 CRISPR knockout $(\mathrm{KO})$ of the porosome protein gene ATP2C1, results in the near absence of

264 detectable levels of ATP2C1 gene product in the ATP2C1 KO Min6 cells [Figure 4]. The

265 colocalization (yellow) of ATP2C1 (red, representing porosome) and insulin (green, representing

266 insulin granules) in SCRM control cells, reflect the docked insulin granules at the porosome

267 [Figure 4]. Very few such colocalizations are seen in the ATP2C1 KO Min6 cells. To further

268 determine whether the expression and distribution of insulin and another porosome-associated

269 protein Syntaxin 1 are affected, immunocytochemistry using Syntaxin 1- and insulin-specific

270 antibody was performed [Figure 5]. Result from this study shows no detectable changes in either

271 the expression or distribution and hence their colocalization of Syntaxin 1 and insulin.

272

273 Knockout of the porosome-associated protein gene ATP2C1 in Min6 cells, results in loss of

274 glucose-stimulated insulin secretion and exosome release

275 Immunoblot analysis of the CRIPSR knockout $(\mathrm{KO})$ of the porosome protein gene ATP2C1 in

276 Min6 cells, demonstrates little expression of the ATP2C1 gene product [Figure 6a]. This further

277 confirms the immunocytochemistry results reported in Figure 5. Exposure of cells to elevated 
278 glucose levels, demonstrate a time-dependent increase in insulin release in both the control and the experimental ATP2C1 KO Min6 cells [Figure 6b, c]. Although little change in the basal levels of

280 insulin release is observed in Min6 cells $(0 \mathrm{~min})$, a significant $(\mathrm{p}<0.05)$ loss in glucose-stimulated

281 insulin secretion is demonstrated after $30 \mathrm{~min}$ following exposure to elevated glucose over controls

282 [Figure 6c]. Additionally, note a loss in the rate of glucose-stimulated insulin secretion from $2830.08 \% / \mathrm{min}$ in the SCRM control Min6 cells to $0.02 \% / \mathrm{min}$ in the ATP2C1 KO Min6 cells.

284 Secretion assays, besides demonstrating that ATP2C1 KO results in a loss of glucose-stimulated 285 insulin secretion, also demonstrate a loss in exosome release [Figure 5b, c, d]. At the 30 min post 286 glucose exposure, CD63 immunoreactivity is detected in Western blots on the resolved incubation 287 medium from SCRM control Min6 cells, while in contrast, the ATP2C1 KO cells, exhibit no 288 detectable signal [Figure 6d]. To test if cells are live and healthy, and to test if DNA is released 289 during glucose stimulation of Min6 cells, the secretion assay medium from all three time points $(0$ $290 \mathrm{~min}, 10 \mathrm{~min}$ and $30 \mathrm{~min}$ ) in SCRM control and ATP2C1 KO was tested for DNA. Except for the 291 standard (M), no detectable DNA bands are observed in the cell medium resolved using agarose 292 gel followed by ethidium bromide staining for all time points in both the control and experimental 293 Min6 cells [Figure 7]. These results demonstrate that the cells are live and healthy throughout the 294 experiment, and that Min6 cells do not release DNA following a glucose challenge.

296 Results from this study further establish the role of the porosome as a universal secretory portal in 297 cells, that regulates the kiss-and-run mechanism of fractional insulin release, and further supports 298 its role in the release of exosomes. Additional ongoing studies in the laboratory utilizing 299 differential expansion microscopy (21) combined with immuno-electron microscopy, will provide 
bioRxiv preprint doi: https://doi.org/10.1101/2022.03.06.483164; this version posted March 6, 2022. The copyright holder for this preprint (which was not certified by peer review) is the author/funder, who has granted bioRxiv a license to display the preprint in perpetuity. It is made available under aCC-BY-NC-ND 4.0 International license.

300 additional clarity to this possible process of porosome-mediated exosome release and the

301 chemistry and biogenesis of these 15-20 nm exosome-like vesicles. 
Acknowledgement: Work presented in this article was supported by the Viron Molecular Medicine Institute.

Conflict: The authors declare no competing financial interests or conflicts.

309 Author Contributions: B.P.J. developed the idea, designed the experiments and wrote the paper. 310 W-J.C. and B.F. performed the immunocytochemistry, CRISPR Knockout and Westerns; M.G.Z. 311 performed electron microscopy on rat brain tissue; D.J.T performed electron microscopy on Min6 312 cells; I.G. participated in the idea development and image analysis. All authors participated in 313 indepth discussions and proofreading the manuscript. The authors thank Daniel A. Walz for critical 314 review of the manuscript.

315

\section{AUTHOR INFORMATION}

\section{Corresponding Author}

318 E-mail: bjena@med.wayne.edu

319 ORCID

320 Bhanu P. Jena: 0000-0002-6030-8766

321 Ionita Ghiran: 0000-0001-6655-3298

322 Mzia Zhvania: 0000-0002-5334-8428

323 Won Jin Cho: 0000-0001-9827-5173 


\section{References}

1. Jena BP. Discovery of the porosome: revealing the molecular mechanism of secretion and membrane fusion in cells. J Cell Mol Med. 2004; 8(1):1-21.

2. Rajagopal A, Kulkarni S, Lewis KT, Chen X, Maarouf A, Kelly CV, Taatjes DJ, Jena its assembly and function. J Proteomics. 2015; 114:83-92. membrane structures involved in exocytosis. Proc Natl Acad Sci USA. 1997; 94:316-21.

5. Jena BP, Cho S-J, Jeremic A, Stromer MH, Abu-Hamdah R. Structure and composition of the fusion pore. Biophys J. 2003; 84:1337-1343.

6. Cho S-J, Jeftinija K, Glavaski A, Jeftinija S, Jena BP, Anderson LL. Structure and dynamics of the fusion pores in live GH-secreting cells revealed using atomic force microscopy. Endocrinology. 2002; 143:1144-1148.

7. Cho WJ, Jeremic A, Rognlien KT, Zhvania MG, Lazrishvili I, Tamar B, Jena BP. Structure, isolation, composition and reconstitution of the neuronal fusion pore. Cell Biol Int. 2004; 28:699-708. 
9. Kovari LC, Brunzelle JS, Lewis KT, Cho W.J, Lee J-S, Taatjes DJ, Jena BP. X-ray solution structure of the native neuronal porosome-synaptic vesicle complex: Implication in neurotransmitter release. Micron. 2014; 56:37-43.

10. Lee J-S, Jeremic A, Shin L, Cho WJ, Chen X, Jena BP. Neuronal porosome proteome: molecular dynamics and architecture. J Proteomics. 2012; 75:952-962.

11. Jena BP. Porosome discovered nearly 20 years ago provide molecular insights into the kiss-and-run mechanism of cell secretion. J Cell Mol Med.2015 May 28. PMID: 26033351. the Insulin-Secreting Porosome Complex in Live Cells. Endocrinology 2016; 157:54-60,

13. Jena BP. Cellular Nanomachines Natures Engineered Marvels. Springer Nature 2020, ISBN: 9783030444952; DOI: 10.1007/978-3-030-44496-9. http://dx.doi.org/10.1016/0092-8674(83)90040-5

15. Pan BT, Teng K, Wu C, Adam M, Johnstone. RM. Electron microscopic evidence for externalization of the transferrin receptor in ve- sicular form in sheep reticulocytes. J. Cell Biol. 1985; 101:942-948. http:// dx.doi.org/10.1083/jcb.101.3.942

16. Kulluri R, Lebleu VS. The biology, function and biomedical application of exosomes. Science 2020; 367(6478):000-000. DOI: 10.1126/science.aau6977 
18. Crescitelli R, Lässer C, Lötvall J. Isolation and characterization of extracellular vesicle population from tissues. Nature Protocols. 2021; 16: 1548-1580.

19. Sugiura A, McLelland G, Fon EA, McBride HM. A new pathway for mitochondrial quality control: mitochondrial-derived vesicles. EMBO J.2014; 33: 2142-2156. doi: 10.15252/embj.201488104

20. She Z, Xie M, Hun M, Abdirahman AS, Li C, Wu F, et al. Immunoregulatory effects of mitochondria transferred by extracellular vesicles. Front. Immunol. 2021; 11:628576. doi: 10.3389/fimmu.2020.628576 R, Naik AR, George K, Arslanturk S, Taatjes DJ, Jena BP. Nanoscale imaging using 


\section{Figure Legends}

391 Figure 1 Electron micrographs of cup-shaped porosome complexes (purple) with docked secretory

392 vesicles (pink) at the cell plasma membrane in the exocrine pancreas (a-c), insulin secreting beta

393 cells of the endocrine pancreas (d-f) and at the nerve terminal in neurons (g-i). (a) Electron

394 micrograph of the apical region of an exocrine pancreatic acinar cell, showing within the green

395 boxed area, a membrane bound secretory vesicle called zymogen granule (ZG) docked at the base

396 of a $100 \mathrm{~nm}$ cup-shaped porosome complex at the cell plasma membrane (Scale bar $=400 \mathrm{~nm})$.

397 Note at greater magnification $(\mathbf{b}, \mathbf{c}),($ Scale bar $=50 \mathrm{~nm})$ the plasma membrane bilayer, the

398 bilayered cup-shaped porosome and the bilayer membrane of ZG are observed. Also note the ring

399 complex at the neck of the porosome (blue arrow heads), proposed to enable the regulated opening

400 and closing of the porosome complex, act via actin and myosin motor proteins. Similarly, cup-

401 shaped porosome complexes are present in the insulin-secreting cells of the endocrine pancreas

402 (d-f) $($ Scale bar $=100 \mathrm{~nm})$. Note a $250 \mathrm{~nm}$ insulin secreting granule $(\mathrm{IG})$ docked, fused and in the

403 process of releasing insulin via the porosome in Min6 cells. (g-i) Cup- shaped 15 nm neuronal

404 porosome complexes at the nerve terminal. Note the central plug within the neuronal porosome

405 complex. (Scale bar $=15 \mathrm{~nm})$. Parts of the images are adopted from our earlier studies $(2,4,7)$, and 406 presented for clarity.

408 Figure 2 Electron micrograph (EM) of rat brain synaptosome showing the association of 15-20

$409 \mathrm{~nm}$ exosome-like vesicles associated with synaptic vesicles, including docked synaptic vesicles at 410 the neuronal porosome complex. Note exosome-like vesicles that appear to be released from the 
411 mitochondria present within the synaptosome compartment (a-d). Pseudo-color of the EM

412 micrographs provide greater clarity.

414 Figure 3 Electron micrograph showing release of exosome-like vesicles and the secretion of

415 insulin via the porosome complex at the plasma membrane in mouse insulinoma Min6 cells. (a, b)

416 Electron micrograph of a Min6 cell, and the nucleus $(\mathrm{N})$, insulin containing electron dense

417 secretory vesicles (red arrowhead) docked at the cell plasma membrane are observed. (c, d) A

418 higher magnification electron micrograph demonstrates an insulin containing granule (red) fused

419 with a multi-vesicular body (purple) containing exosomes (blue). The fused insulin granule and

420 multi-vesicular body complex is seen docked at the porosome base and in the process of releasing

421 exosome-like vesicles and insulin to the cell exterior. Note the $100 \mathrm{~nm}$ porosome complex, the 150

$422 \mathrm{~nm}$ in diameter insulin granule, and the $15-20 \mathrm{~nm}$ exosomes being extruded from the cell via the

423 porosome complex.

425 Figure 4 Immunofluorescent microscopy demonstrates the loss of ATP2C1 expression in ATP2C1

426 KO Min6 cells. Note however, that the expression and distribution of insulin and the porosome

427 protein Syntaxin 1 in Min6 cells, or the morphology of the nucleus (DAPI blue) remain unaffected

428 by the ATP2C1 KO. (a) Robust expression of ATP2C1 protein immunoreactivity is observed in

429 the perinuclear Golgi region and at the cell periphery (plasma membrane) in SCRM control Min6

430 cells. Also note the yellow fluorescence, indicating co-localization of the porosome-associated

431 ATP2C1 gene product and insulin containing granules in the control SCRM Min6 cells. In contrast

432 in the $\mathrm{ATP} 2 \mathrm{C} 1 \mathrm{KO}$ cells, the expression $\mathrm{ATP} 2 \mathrm{C} 1$ is greatly reduced, resulting in an increase in 
undocked insulin containing granules (green) (b). The DAPI stained nucleus and the overall cell morphology in both the SCRM and ATP2C1 KO appears indistinguishable. Scale bar $=10 \mu m$.

Figure 5 Immunofluorescent microscopy reflecting the unaffected expression and distribution of

437 the porosome protein Syntaxin 1 and insulin containing secretory granules in SCRM control and 438 in the ATP2C1 KO Min6 cells. (a-f) Note the circular patches of Syntaxin 1 immunoreactivity 439 (porosomes) and the punctate insulin immunoreactivity representing the distribution of insulin 440 containing granules. The merged images in (c) and (d) and their assessment using Pearson 441 Correlation Coefficient (g), reflect no difference between the SCRM controls and the ATP2C1 KO $442(n=3)$. These results further suggest that certain porosomes in Min6 cells may be devoid of the 443 ATP2C1 gene product. Scale bar $=20 \mu m$.

Figure 6 Immunoblot analysis demonstrates that there is significant loss of ATP2C1 expression

446 in ATP2C1 KO Min6 cells, and that this absence of the porosome-associated protein results in a 447 loss of both glucose-stimulated insulin secretion and exosome release. (a) Note the near absence 448 of immunodetectable ATP2C1 gene product in the ATP2C1 KO Min6 cell homogenate compared 449 to the SCRM control. (b) Immunoblot analysis of $5 \mu \mathrm{g}$ of total Min6 cell homogenate (TH) from 450 SCRM and ATP2C1 KO Min6 cells, and equal volumes of Min6 cell incubation medium (PBS) at 451 different times following a glucose challenge, were resolved using SDS-PAGE followed by 452 electrotransfer to nitrocellulose membrane and probed using the insulin-specific antibody and or 453 the exosome-specific antibody CD63. Note the significant loss in both the potency and efficacy of 454 glucose-stimulated insulin secretion in ATP2C1 KO Min6 cells compared to SCRM controls $(\mathrm{n}=5)$

455 (b, c). Similarly, undetectable levels of the CD63 immunoreactivity in the ATP2C1 KO cell 
456 incubation media following $30 \mathrm{~min}$ of glucose stimulation is observed, which in contrast is clearly

457 observed in the 30 min SCRM control medium (despite the high dilution).

459 Figure 7 Min6 cells exposed to glucose for up to $30 \mathrm{~min}$ are healthy and intact, and do not release

460 DNA. Agarose gel electrophoresis performed on a positive control DNA sample and Min6 cells

461 (both SCRM and ATP2C1 KO) incubation medium following glucose challenge, demonstrate no

462 release of the nucleotide at any time point post glucose challenge. These results additionally reflect

463 that the viability and integrity of Min6 cells are intact throughout the course of the experiment. 
bioRxiv preprint doi: https://doi.org/10.1101/2022.03.06.483164; this version posted March 6, 2022. The copyright holder for this preprint (which was not certified by peer review) is the author/funder, who has granted bioRxiv a license to display the preprint in perpetuity. It is made available under aCC-BY-NC-ND 4.0 International license.

Fig. 1.

466
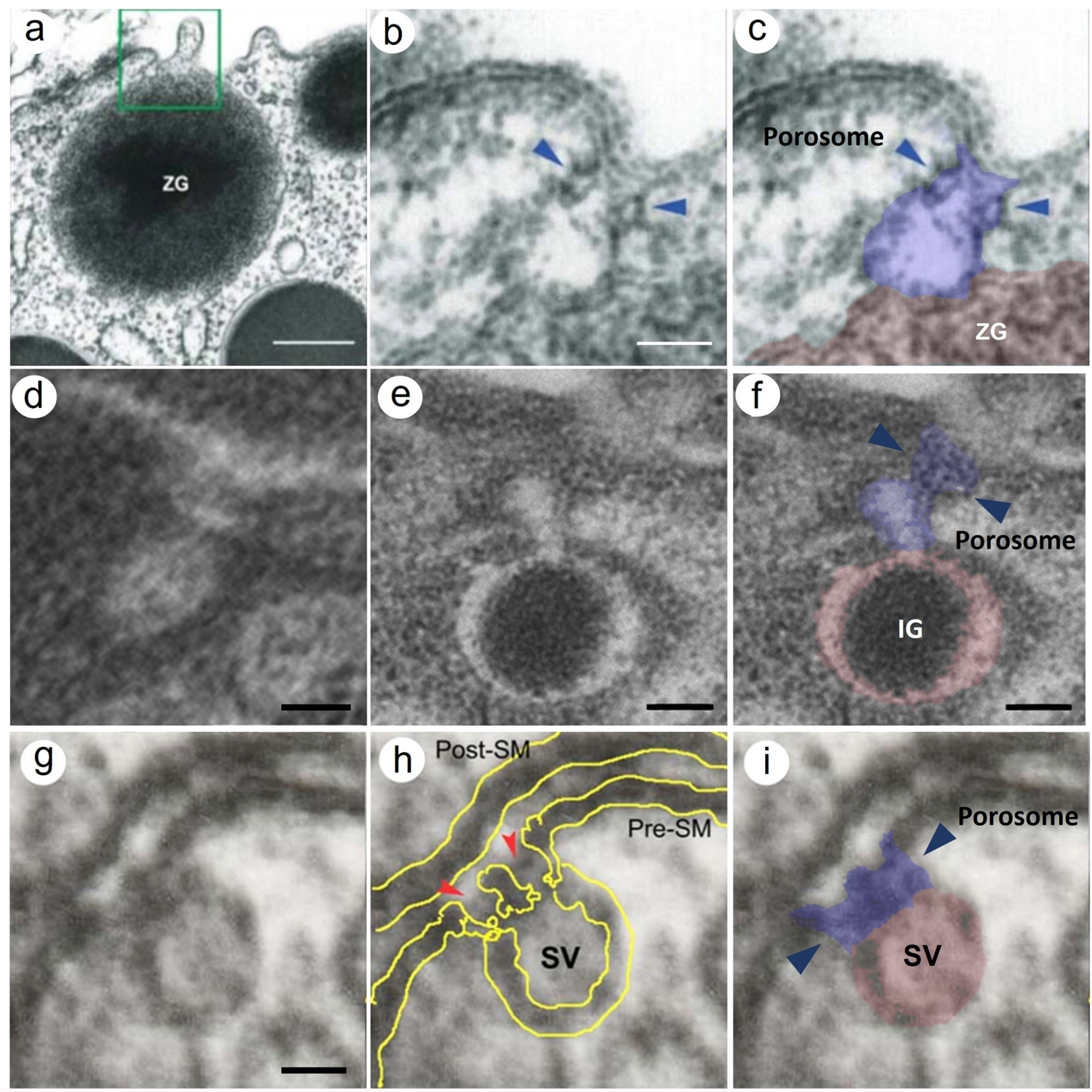
bioRxiv preprint doi: https://doi.org/10.1101/2022.03.06.483164; this version posted March 6. 2022. The copyright holder for this preprint (which was not certified by peer review) is the author/funder, who has granted bioRxiv a license to display the preprint in perpetuity. It is made available under aCC-BY-NC-ND 4.0 International license.

Fig. 2.

472

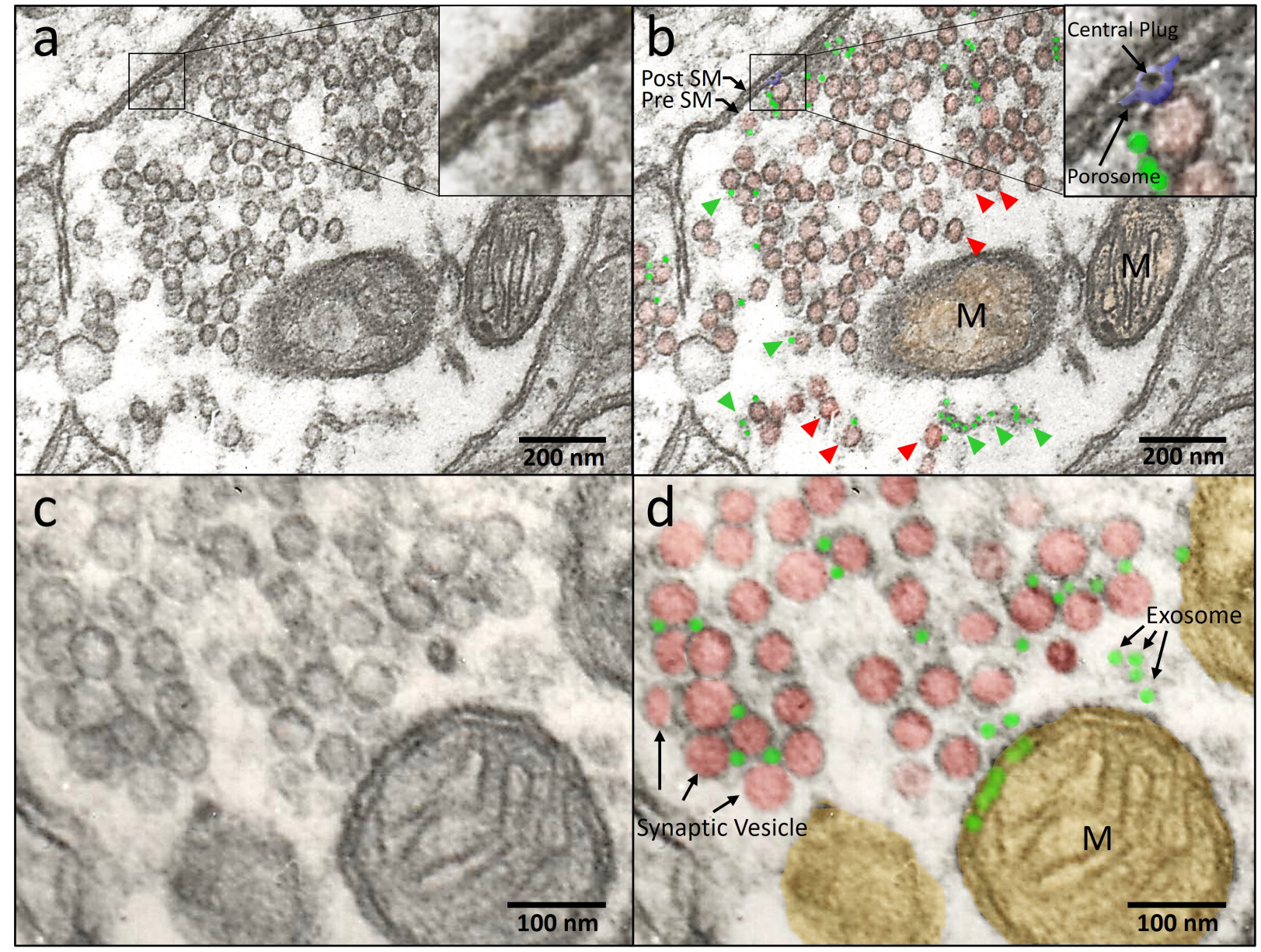


bioRxiv preprint doi: https://doi.org/10.1101/2022.03.06 483164; this version posted March 6. 2022. The copyright holder for this preprint (which was not certified by peer review) is the author/funder, who has granted bioRxiv a license to display the preprint in perpetuity. It is made available under aCC-BY-NC-ND 4.0 International license.

$475 \quad$ Fig. 3.

476

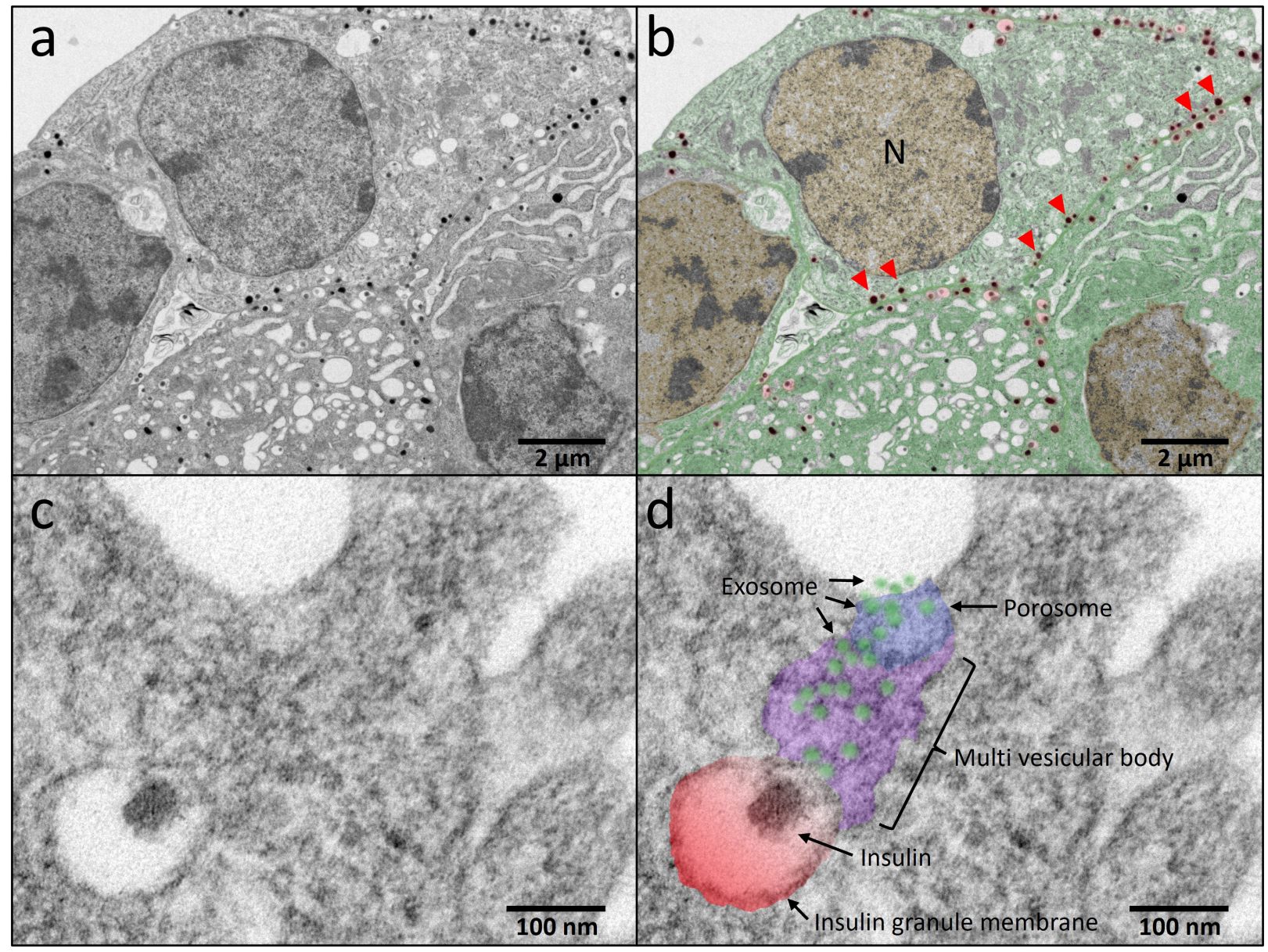


bioRxiv preprint doi: https://doi.org/10.1101/2022.03.06.483164; this version posted March 6, 2022. The copyright holder for this preprint (which was not certified by peer review) is the author/funder, who has granted bioRxiv a license to display the preprint in perpetuity. It is made available under aCC-BY-NC-ND 4.0 International license.

$479 \quad$ Fig. 4.

480

481

SCRM

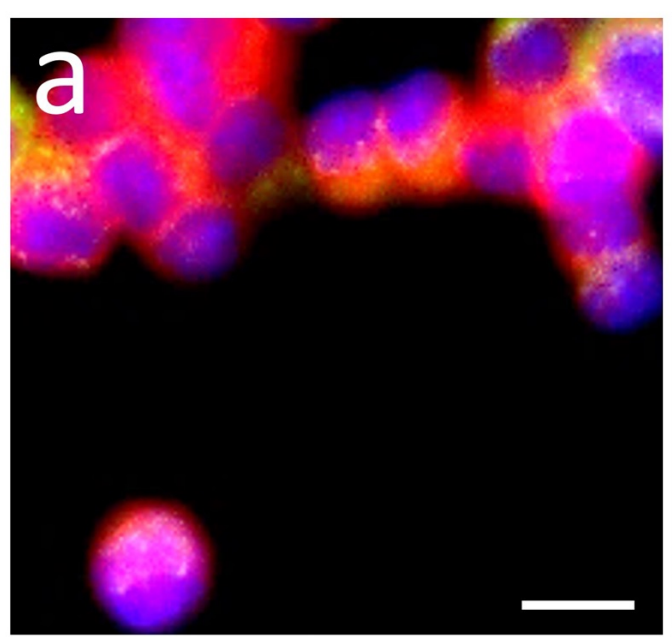

KO-ATP2C1

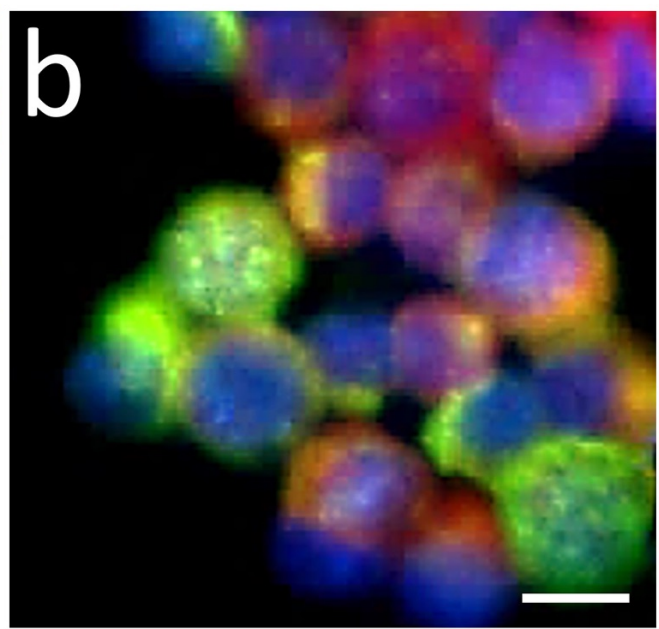


bioRxiv preprint doi: https://doi.org/10.1101/2022.03.06.483164; this version posted March 6, 2022. The copyright holder for this preprint (which was not certified by peer review) is the author/funder, who has granted bioRxiv a license to display the preprint in perpetuity. It is made available under aCC-BY-NC-ND 4.0 International license.

$483 \quad$ Fig. 5.

484

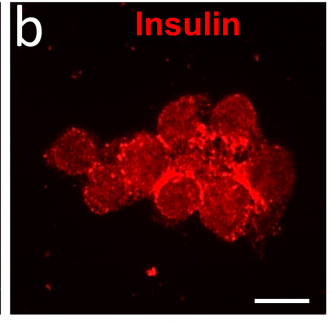

KO-

ATP2C1

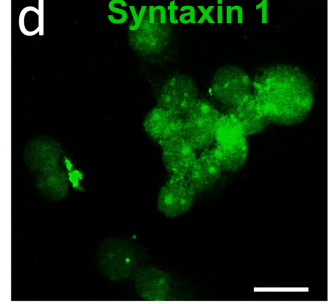

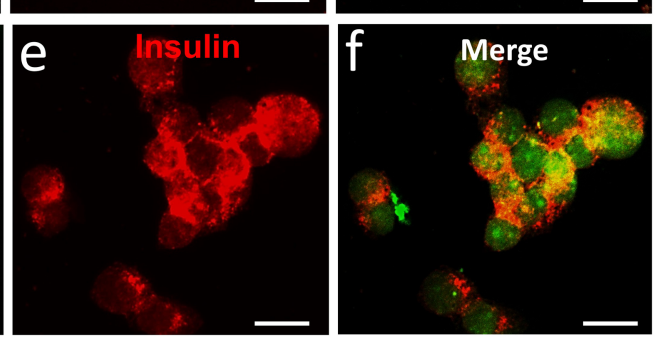

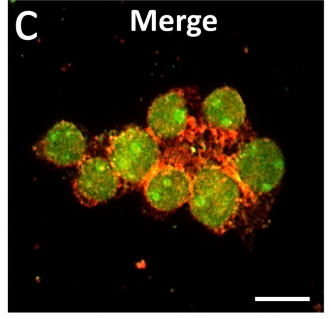

g

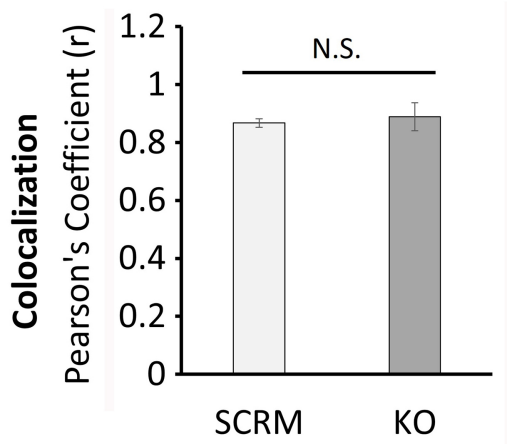

486 
Fig. 6 .

488

a

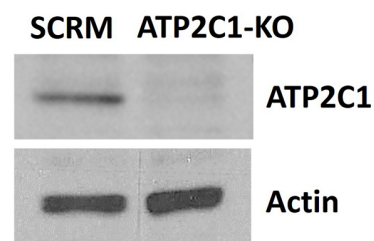

b

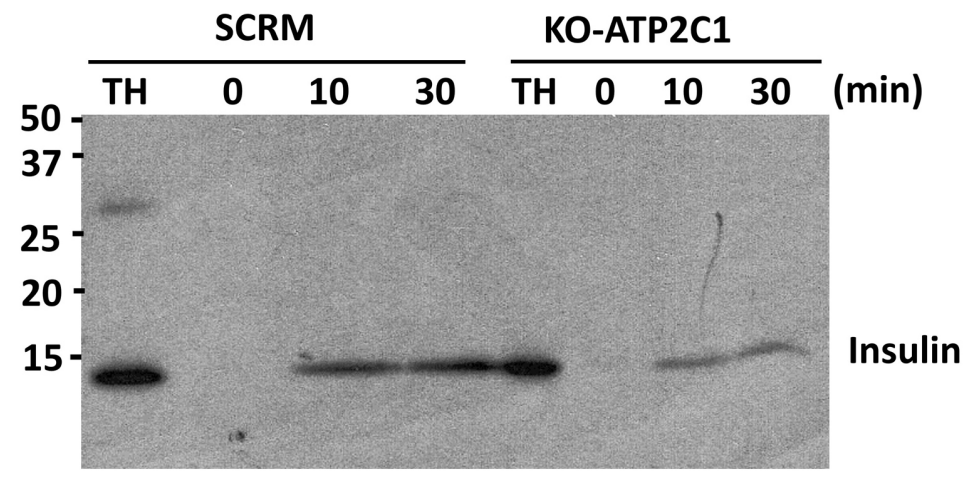

C

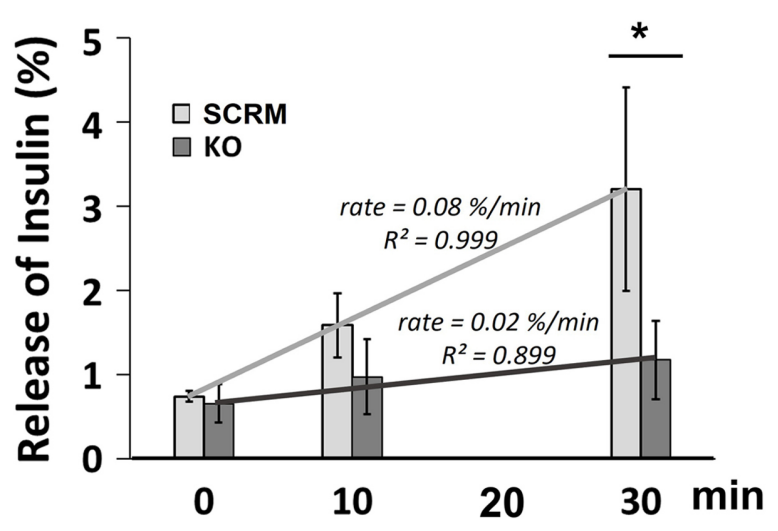

d $\frac{\text { SCRM }}{\text { KO-ATP2C1 }}$

\begin{tabular}{lllllllll}
\hline TH & 0 & 10 & 30 & TH & 0 & 10 & 30 & (min)
\end{tabular}

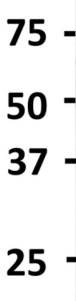


$491 \quad$ Fig. 7.

492

SCRM M

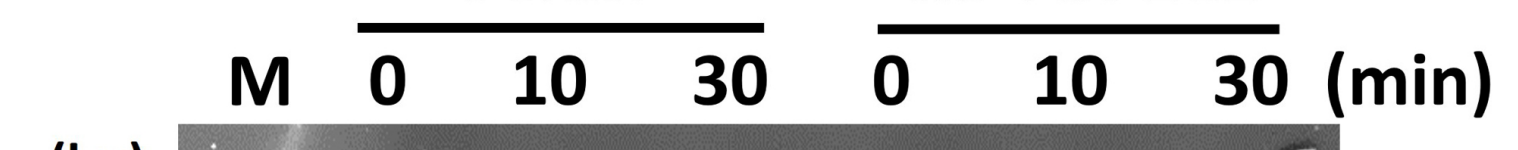
KO-ATP2C1 


\section{SUMMARY}

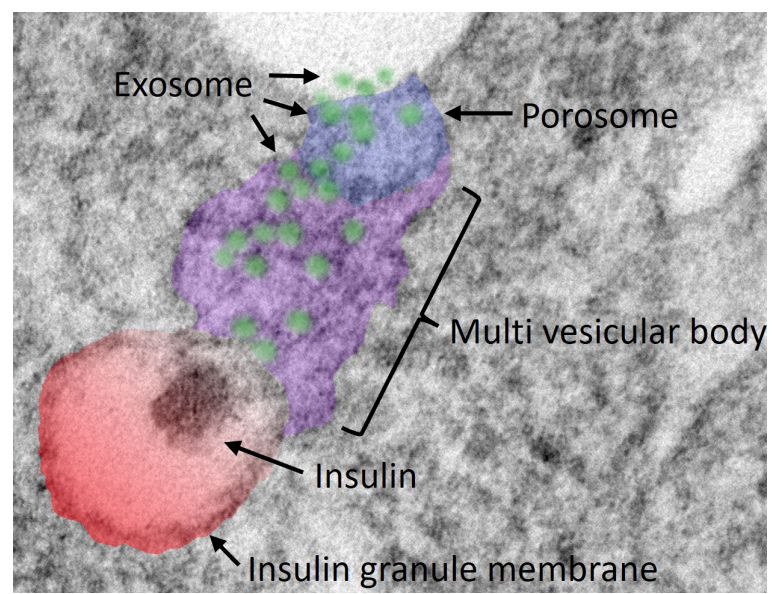

500 Exosomes and insulin are secreted through the porosome complex in mouse insulinoma Min6 cell.

501 Electron micrograph demonstrates an insulin containing granule (red) fused with a multi-vesicular

502 body (purple) containing exosomes (blue), docked at the porosome base and in the process of 503 releasing exosomes to the cell exterior. 